\title{
Adequação da metodologia do teste de tetrazólio para sementes de Hymenachne amplexicaulis
}

\author{
Methodology adequation of tetrazolium test for Hymenachne \\ amplexicaulis seeds
}

\author{
Keli Souza da Silva ${ }^{1 *}$; Sérgio Luiz de Oliveira Machado²; Nilson Lemos de \\ Menezes $^{3}$; Leonardo José Kurtz Urban ${ }^{4}$; Marcos Vinícius Palma Alves ${ }^{4}$
}

\section{Resumo}

O Hymenachne amplexicaulis é uma gramínea considerada invasora da cultura do arroz irrigado. Suas sementes medem cerca de três milímetros de comprimento e uma panícula pode produzir grande número de sementes viáveis. Este trabalho teve por objetivo, estabelecer a metodologia adequada para avaliar a viabilidade de sementes de $H$. amplexicaulis, usando o teste de tetrazólio. Os ensaios, com delineamento experimental inteiramente casualizado, foram conduzidos no laboratório de Herbologia e no laboratório Didático e de Pesquisa em Sementes da Universidade Federal de Santa Maria, em 2010. Para o teste de germinação, tratamentos com sementes protegidas pelas suas glumas e desprovidas dessas (nuas) foram expostas ao nitrato de potássio, na concentração de $0,2 \%$ ou água destilada (testemunha). Para o teste de tetrazólio, sementes nuas foram embebidas diretamente em água por períodos de 6, 12 e 24 horas, a temperatura de $23^{\circ} \mathrm{C} \pm 1{ }^{\circ} \mathrm{C}$. Posteriormente, as sementes foram mantidas em solução de 2,3,5-trifenil cloreto de tetrazólio na concentração de $0,5 \%$, na referida temperatura e acompanhando-se a evolução da coloração. As sementes foram classificadas como viáveis ou não viáveis, conforme parâmetro préestabelecido, seguindo-se à análise dos dados. A embebição em água das sementes sem glumas, durante seis horas, com posterior imersão em solução de tetrazólio a $0,5 \%$ por quatro horas foi eficiente na determinação da viabilidade das sementes.

Palavras-chave: Capim-capivara, teste rápido, viabilidade

\begin{abstract}
The Hymenachne amplexicaulis is a grass, considered a weed in the flooded Rice. Its seeds, measure about three millimeters in length and its panicles can produce a large number of viable seeds. This study aimed to establish the appropriate methodology for evaluate the viability of seeds of $H$. amplexicaulis using tetrazolium test. The tests, with completely randomized design, were conducted in the Herbology Didactic of Laboratory and Seed Laboratory for Didactic and Research, Universidade Federal de Santa Maria in 2010. For the germination test, treatments seed protected by their glumes and without these (naked) were exposed to potassium nitrate at a concentration of $0.2 \%$ or distilled water (control). For the tetrazolium test, naked seeds were immersed directly in water for 6,12 and 24 hours periods at $23^{\circ} \mathrm{C}$ $\pm 1^{\circ} \mathrm{C}$. Subsequently, the seeds were incubated in a solution of 2,3,5-triphenyl tetrazolium chloride at a concentration of $0.5 \%$, at this temperature and followed-up the evolution of coloration. The seeds were
\end{abstract}

\footnotetext{
${ }^{1}$ Enga Agr $^{\mathrm{a}}$, Doutoranda do Programa de Pós-graduação em Agronomia, Universidade Federal de Santa Maria, UFSM, Santa Maria, RS. E-mail: keli_agro@yahoo.com.br

${ }^{2}$ Prof. Titular do Dept $^{\circ}$ de Defesa Fitossanitária, Centro de Ciências Rurais da UFSM, Santa Maria, RS. E-mail: slomachado@, yahoo.com.br

${ }^{3}$ Prof. Associado, Aposentado do Dept ${ }^{\mathrm{o}}$ de Fitotecnia, UFSM, Santa Maria, RS. E-mail: nlmenezes@hotmail.com

${ }^{4}$ Discente(s) do curso de Agronomia, UFSM, Santa Maria, RS. E-mail: urban_686@hotmail.com; marcosvpalves@gmail.com

* Autor para correspondência
} 
classified as viable or non-viable, according with parameter predetermined, followed by data analysis. The imbibition of seeds without glumes, for six hours, with subsequent immersion in a solution of tetrazolium $0.5 \%$ for four hours was effective in determining the viability of seeds.

Key words: West indian marsh grass, quick test, viability

A espécie Hymenachne amplexicaulis (Rudge) Nees, conhecida como capim-capivara, é uma gramínea nativa das Américas Central e Sul, que apresenta pleno crescimento em regiões pantanosas, margens de rios e áreas temporariamente alagadas. Autores como Sturza et al. (2011) relataram sua ocorrência como infestante em áreas cultivadas com arroz irrigado no Rio Grande do Sul (RS), Brasil. Esta espécie propaga-se por fragmentos de rizomas, estolões e ainda, por sementes (CSURHES; MACKEY; FITZSIMMONS, 1999).

Suas sementes, de tamanho reduzido, medem em média três milímetros de comprimento e suas panículas, com até $40 \mathrm{~cm}$, produzem grande número de sementes viáveis. Uma única panícula pode produzir mais de 4 mil sementes (CHARLESTON, 2006), com $98 \%$ de viabilidade, mantendo-se viáveis mesmo após 16 meses de armazenamento em ambiente, com temperatura entre 20 e $30^{\circ} \mathrm{C}$. Ensaios de longevidade e germinação em profundidade $(0,2$ a $10 \mathrm{~cm})$ demonstraram, após quatro anos, germinação de sementes entre 20 e $65 \%$, dependendo da profundidade (AGRICULTURE..., 2000). As sementes, por meio de mecanismos de dormência, podem sobreviver nos corpos d'água e germinar quando o nível diminuir (CHARLESTON, 2006).

A dormência, uma característica fisioecológica e peculiar a cada espécie (LACERDA et al., 2010), é o processo que inibe a germinação de sementes viáveis de muitas plantas, fazendo com que não germinem mesmo quando os fatores externos necessários ao processo de germinação, como a disponibilidade de luz, água e oxigênio, sejam adequados (EIRA; FREITAS; MELLO, 1993), distribuindo a germinação ao longo do tempo e possibilitando um fluxo de emergência, de modo a produzir plântulas em diversas condições, favoráveis ou não, ao seu desenvolvimento.
$\mathrm{O}$ processo de dormência ocorre com freqüência em sementes de plantas daninhas, e pode ser considerado como responsável pela sobrevivência dessas espécies e a pela manutenção das suas populações em ambientes instáveis. É essa habilidade, dentre outras, que permite às plantas consideradas daninhas, a incorporação e manutenção de seus propágulos, no banco de sementes do solo, garantindo assim, a perpetuação da espécie (VIVIAN et al., 2008). Nesse sentido, ao identificar a ocorrência de dormência em sementes de plantas daninhas, o teste de tetrazólio indica, rapidamente, o percentual de sementes viáveis, portanto, passíveis de germinar e dar origem a novas plantas.

O teste é baseado na utilização da solução salina incolor de cloreto de 2,3,5-trifenil tetrazólio, que ao ser absorvida pelas sementes é reduzida pela atividade de enzimas desidrogenases (NERY; CARVALHO; OLIVEIRA, 2007), presentes nos tecidos vivos, resultando na formação de um composto estável e de coloração vermelha, o trifenilformazan. Logo, as regiões com atividade respiratória nas mitocôndrias se mostram avermelhadas, portanto, vivas, enquanto os tecidos mortos não reagem à solução, mantendo sua cor natural (FRANÇA NETO; KRZYZANOWSKI; COSTA, 1999).

Metodologias para a elaboração do teste, que exige prévia embebição em água e posterior coloração, são descritas por Brasil (2009) e outros autores, entretanto, características intrínsecas a diversas espécies exigem tempo de exposição, temperaturas e concentrações peculiares, requerendo metodologias específicas. Assim, este trabalho teve por objetivo, estabelecer a metodologia adequada para a avaliação da viabilidade das sementes de Hymenachne amplexicaulis, por meio do teste de tetrazólio. 
Os ensaios foram conduzidos no laboratório de Herbologia Professor Loreno Covolo, do Departamento de Defesa Fitossanitária, e no laboratório Didático e de Pesquisa em Sementes, do Departamento de Fitotecnia, ambos na Universidade Federal de Santa Maria, no município de Santa Maria, RS, em 2010. As sementes utilizadas, provenientes de área cultivada com arroz irrigado, localizada no município de Formigueiro (RS), foram coletadas em fevereiro do mesmo ano, quando constatado o início do degrane natural das cariopses. Para tal, as panículas foram agitadas dentro de sacos de papel, a fim de uniformizar o estádio das sementes no momento da coleta. Posteriormente, foram encaminhadas ao laboratório, onde permaneceram sob refrigeração $\left(10 \pm 2{ }^{\circ} \mathrm{C}\right)$ pelo período de seis meses, precedendo-se aos testes.

Para a determinação do teor de água das sementes, foi adotado o método da estufa a $105^{\circ} \mathrm{C}$ $\pm 3^{\circ} \mathrm{C}$, por 24 horas (BRASIL, 2009), utilizando quatro repetições de cinco gramas de sementes acondicionadas em recipientes de alumínio, sendo o grau de umidade, calculado por diferença de massa, com base na massa úmida das sementes. Para o teste de germinação, tratamentos com sementes protegidas pelas suas glumas e desprovidas dessas (nuas) foram expostas ao promotor de germinação nitrato de potássio $\left(\mathrm{KNO}_{3}\right)$, na concentração de $0,2 \%$ ou a água destilada (testemunha). O teste foi realizado em caixas plásticas do tipo gerbox, sobre papel filtro umedecido com 2,5 vezes seu peso, com os respectivos tratamentos $\left(\mathrm{KNO}_{3}\right.$ ou água), mantidas em germinador ajustado com temperatura alternada entre 20 e $30^{\circ} \mathrm{C}$ e fotoperíodo de 12 horas. As avaliações, realizadas diariamente, computaram percentual de sementes que originaram plântulas normais e a partir deste, o índice de velocidade de germinação (IVG) (MAGUIRE, 1962). O teste foi encerrado no décimo dia, com a germinação máxima de uma repetição e conforme o indicado para algumas gramíneas estivais (BRASIL, 2009).
Para o teste de tetrazólio, devido ao diminuto tamanho e a conseqüente dificuldade para retirar os envoltórios após a embebição, as glumas foram retiradas com as sementes secas. Para a embebição direta em água utilizou-se como tratamentos, períodos de 6,12 e 24 horas, a temperatura de $23^{\circ} \mathrm{C} \pm$ $1{ }^{\circ} \mathrm{C}$ (ambiente). Após o período de embebição, foram feitos cortes longitudinais conforme o preconizado para sementes pequenas de gramíneas (BRASIL, 2009) e imersão em solução de 2,3,5-trifenil cloreto de tetrazólio, em frascos escuros.

Para sementes de gramíneas são indicadas concentrações de 0,5 a 1\% de tetrazólio (BRASIL, 2009), utilizando-se neste ensaio a menor concentração recomendada, com avaliação da coloração a cada hora após a imersão, atingindo a adequada coloração dos embriões após quatro horas, a temperatura de $23^{\circ} \mathrm{C} \pm 1^{\circ} \mathrm{C}$. Em seguida, as sementes foram retiradas, lavadas e mantidas em água destilada e os embriões e endospermas analisados com o auxílio de lupa, considerandose viáveis as sementes que apresentaram a região embrionária corada uniformemente, conforme parâmetro estabelecido com sementes viáveis e não viáveis (Figura 1).

Todos os testes foram conduzidos no delineamento inteiramente casualizado, com quatro repetições de 50 sementes. Os resultados, expressos em porcentagem, foram testados quanto à normalidade, quando necessário, transformados utilizando-se a expressão $\operatorname{arcsen} \sqrt{x / 100}$, e submetidos a analise da variância. As médias dos tratamentos para superação da dormência foram separadas pelo teste de Tukey $(\mathrm{p} \leq 0,05)$, selecionando-se o melhor tratamento como testemunha para a comparação com os resultados do teste de tetrazólio. 
Figura 1. Sementes de Hymenachne amplexicaulis (aumento de 25 vezes) consideradas viáveis (a e b) e inviáveis (c e d), segundo teste de tetrazólio. Endosperma (1) e embrião (2). Santa Maria (RS), 2010.
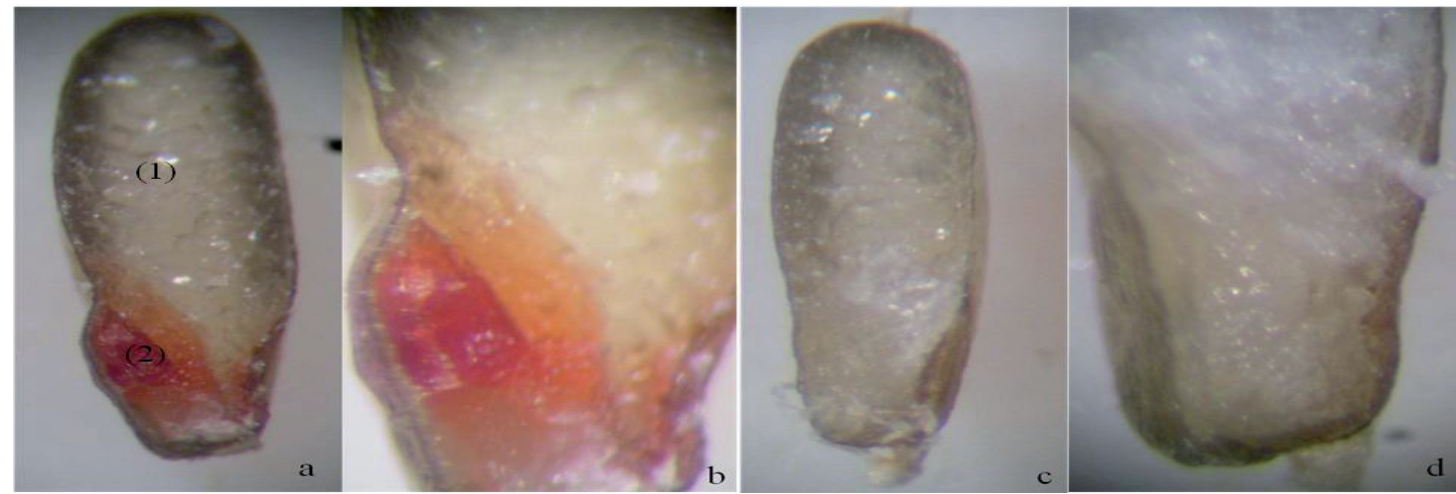

Fonte: Elaboração dos autores.

O grau médio de umidade das sementes utilizadas foi de $10,8 \%$. Os períodos de embebição em água utilizados acarretaram diferentes respostas quanto ao a viabilidade das sementes analisadas. Dentre estes, o período de seis horas apresentou percentuais de viabilidade semelhantes aos percentuais de germinação encontrados para os tratamentos onde as glumas das sementes foram removidas (testemunha). Os demais períodos de embebição avaliados, 12 e 24 horas, não diferiram significativamente entre si, mostrando-se inadequados para a espécie, visto que os resultados de viabilidade encontrados divergiram dos resultados de germinação. Os percentuais de germinação e viabilidade dos tratamentos estão expostos na Tabela 1.

Tabela 1. Percentual de germinação, índice de velocidade de germinação e percentual de viabilidade, determinado pelo teste de tetrazólio, de sementes de Hymenachne amplexicaulis. Santa Maria, RS. 2010.

\begin{tabular}{lcclc}
\hline \multicolumn{1}{c}{ Tratamento } & Germinação & IVG & \multicolumn{1}{c}{ Tratamento } & Viabilidade \\
\hline Semente nua $+\mathrm{KNO}_{3}$ & $89 \mathrm{a}^{*}$ & $29,0 \mathrm{a}$ & Testemunha & $90 \mathrm{a}$ \\
Semente nua + água & $91 \mathrm{a}$ & $28,1 \mathrm{a}$ & Seis horas & $89 \mathrm{a}$ \\
Semente protegida $+\mathrm{KNO}_{3}$ & $59 \mathrm{~b}$ & $13,2 \mathrm{~b}$ & Doze horas & $22 \mathrm{~b}$ \\
Semente protegida + água & $0 \mathrm{c}$ & $0 \mathrm{c}$ & Vinte e quatro horas & $28 \mathrm{~b}$ \\
\hline \multicolumn{1}{c}{ C.V. ${ }^{1}(\%)$} & 11,57 & 12,69 & C.V. $(\%)$ & 11,20 \\
\hline
\end{tabular}

Médias seguidas por letras minúsculas distintas diferem entre si pelo teste de Tukey $(\mathrm{p} \leq 0,05) .{ }^{1}$ Coeficiente de variação.

Fonte: Elaboração dos autores.

A similaridade dos resultados de germinação e viabilidade entre os tratamentos de sementes nuas e seis horas de embebição pode ser explicada pela presença, nas glumas, de agentes causadores de dormência nas sementes dessa espécie. Sem as glumas, as sementes germinaram rapidamente, expressando todo o seu potencial germinativo. Ao estudar a superação de dormência em sementes de Brachiaria decumbens Stapf., Jark Filho (1976) removeu glumas e glumelas, concluindo que este tratamento permite avaliar o potencial germinativo, independentemente do grau de dormência apresentado pelas sementes. Ao trabalhar com a mesma espécie, Carneiro e Marques (1985) 
concluíram que a remoção da lema e da pálea favoreceu a germinação em todos os tratamentos, atingindo percentuais de $95 \%$.

Os tratamentos onde as glumas foram removidas tiveram o processo de germinação acelerado em relação ao tratamento de sementes protegidas pelos envoltórios combinado com $\mathrm{KNO}_{3}$, como demonstra o IVG, o que motivou o encerramento do teste quando ocorreu a germinação de todas as sementes de uma repetição das sementes nuas. Este fato pode explicar o menor percentual de germinação do tratamento de sementes protegidas $+\mathrm{KNO}_{3}$, além, da possibilidade de superação insuficiente da dormência, como visto com ácido sulfúrico, em sementes de braquiária (Brachiaria brizantha (Hochst. ex A. Rich.) Stapf.) (DIAS; ALVES, 2008). A não germinação das sementes protegidas pelas glumas e embebidas somente em água, quando comparada aos percentuais de viabilidade, expressos pelo teste de tetrazólio demonstra a possível presença de dormência nas sementes, que provavelmente mantiveram sua qualidade fisiológica devido à temperatura na qual foram armazenadas.

A remoção das glumas das sementes ainda secas, antes do período de pré-condicionamento para o teste de tetrazólio, pode reduzir significativamente os danos causados às sementes de tamanho reduzido, do que quando estas já estiverem hidratadas. O período de hidratação, durante o pré-condicionamento, influencia no teor de água das sementes, tornando-se um fator importante para a qualidade da coloração. De acordo com Moore (1977), a hidratação promove o amolecimento dos tecidos da semente, facilitando o preparo e a absorção da solução de tetrazólio, além de ativar o sistema enzimático, o que resulta em coloração mais nítida. Em algumas espécies, as glumas podem impor uma barreira à absorção de água, e sua remoção facilita esse processo. Entretanto, a exposição por tempo excessivo em água pode acarretar a redução da disponibilidade de oxigênio para as sementes (LIMA et al., 2004), levando a resultados incorretos. Este fato pode explicar a baixa viabilidade das sementes quando embebidas sem seus envoltórios, pelos períodos de 12 e 24 horas.

Ao avaliar períodos de embebição e temperaturas para o teste de tetrazólio em sementes de B. brizantha, Novembre, Chamma e Gomes (2006) indicaram seis horas de embebição a $30^{\circ} \mathrm{C}$, com posterior período de duas horas a $40^{\circ} \mathrm{C}$, em solução de tetrazólio a $0,075 \%$, como tratamento adequado para avaliar a viabilidade das sementes dessa espécie. Em sementes de Hymenachne amplexicaulis, o teste de tetrazólio mostrou-se como uma importante ferramenta, complementando o teste de germinação, a fim de avaliar a viabilidade das sementes e a eficiência de tratamentos utilizados para sua superação.

A embebição em água, de sementes de Hymenachne amplexicaulis, sem glumas, durante seis horas a $23 \pm 1{ }^{\circ} \mathrm{C}$, com posterior imersão em solução de tetrazólio a $0,5 \%$ por quatro horas é eficiente na avaliação da viabilidade das sementes.

\section{Referências}

AGRICULTURE \& RESOURCE MANAGEMENT COUNCIL OF AUSTRALIA \& NEW ZEALAND, AUSTRALIAN \& NEW ZEALAND ENVIRONMENT \& CONSERVATION COUNCIL AND FORESTRY MINISTERS. Weeds of National significance Hymenachne (Hymenachne amplexicaulis) strategic plan. National Weeds Strategy Executive Committee, Launceston. 2000. Available at: <http://www.dpi.qld. gov.au/documents/Biosecurity_EnvironmentalPests/ IPA-Hymenachne-Nsplan.pdf.>. Accessed at: $12 \mathrm{dez}$. 2010.

BRASIL. Ministério da Agricultura, Pecuária e Abastecimento. Regras para análise de sementes. Ministério da Agricultura, Pecuária e Abastecimento. Secretaria de Defesa Agropecuária. Brasília, DF: Mapa/ ACS, 2009. 395 p.

CARNEIRO, J. W. P.; MARQUES, F. V. Influência da retirada da cobertura protetora no desempenho de dois lotes de sementes de capim braquiária. In: CONGRESSO BRASILEIRO DE SEMENTES, 4., Brasília, 1985. Resumos... Brasília: ABRATES, 1985. p. 81. 
CHARLESTON, K. Hymenachne (Hymenachne amplexicaulis) management. Control methods and case studies. 2006. Available at: <http://resourceeconomics. cqu.edu.au/FCWViewer/getFile.do?id=7443.>. Accessed at: 02 mar. 2010.

CSURHES, S. M.; MACKEY, A. P.; FITZSIMMONS, L. Hymenachne (Hymenachne amplexicaulis) in Queensland. Pest Status Review Series. Land Protection Dept. of Nat. Resour. Queensland, Australia, 43 p. 1999. Available at: <www.nrm.qld.gov.au/pests/psas/pdfs/ Hymenachne.pdf $>$. Available at: 03 jan. 2010.

DIAS, M. C. L. L.; ALVES, S. J. Avaliação da viabilidade de sementes de Brachiaria brizantha (Hochst. ex A. Rich) Stapf pelo teste de tetrazólio. Revista Brasileira de Sementes, Londrina, v. 30, n. 3, p. 145-151, 2008.

EIRA, M. T. S.; FREITAS, R. W. A.; MELLO, C. M. C. Superação da dormência de sementes de Enterolobium contortisiliquum (Vell.) Morong. - Leguminosae. Revista Brasileira de Sementes, Londrina, v. 15, n. 2, p. 177-181, 1993.

FRANÇA NETO, J. B.; KRZYZANOWSKI, F. C.; COSTA, N. P. Metodologia do teste de tetrazólio em sementes de soja. In: KRZYZANOWSKI, F. C.; VIEIRA, R. D.; FRANÇA NETO, J. B. (Ed.). Vigor de sementes: conceitos e testes. Londrina: ABRATES, 1999. cap. 8.5, p. 1-28.

JARK FILHO, W. Estudo sobre a quebra de dormência em sementes de Brachiaria decumbens Stapf. 1976. Dissertação (Mestrado em Fitotecnia) - Escola Superior de Agronomia Luiz de Queiroz, Piracicaba.

LACERDA, M. J. R.; CABRAL, J. S. R.; SALES, J. F.; FREITAS, K. R.; FONTES, A. J. Superação da dormência de sementes de Brachiaria brizantha cv. "Marandu". Semina: Ciências Agrárias, Londrina, v. 31, n. 4, p. 823828, out./dez. 2010.
LIMA, S. M. P.; GUIMARAES, R. M.; OLIVEIRA, J. A.; VIEIRA, M. G. G. C. Efeitos de tempos e temperaturas de condicionamento sobre a qualidade fisiológica de sementes de cafeeiro (Coffea arabica, L.) sob condições ideais de estresse térmico. Ciência Agrotécnica, Lavras, v. 28, n. 3, p. 505-14, 2004.

MAGUIRE, J. D. Speed of germination - aid in selection and evaluation for seedling and vigour. Crop Science, Madison, v. 2, n. 2, p. 176-177, 1962.

MOORE, R. P. Tetrazolium testing handbook. Raleigh: North Carolina State University, 1977.

NERY, M. C.; CARVALHO, M. L. M.; OLIVEIRA, L. M. Teste de tetrazólio para avaliação da qualidade fisiológica de sementes de melancia. Semina: Ciências Agrárias, Londrina, v. 28, n. 3, p. 365-372, jul./set. 2007.

NOVEMBRE, A. D. L. C.; CHAMMA, H. M. C. P.; GOMES, R. B. R. Viabilidade das sementes de braquiária pelo teste de tetrazólio. Revista Brasileira de Sementes, Pelotas, v. 28, n. 2, p. 147-151, 2006.

STURZA, V. S.; MACHADO, S. L. O.; SILVA, K. S.; SANTOS, A. B. Qualidade forrageira do capim-capivara em áreas de várzea, na região central do Rio Grande do Sul, Brasil. Ciência Rural, Santa Maria, v. 41, n. 5, p. 883-887, 2011

VIVIAN, R.; SILVA, A. A.; GIMENES JUNIOR, M.; FAGAN, E. B.; RUIZ, S. T.; LABONIA, V. Dormência em sementes de plantas daninhas como mecanismo de sobrevivência - breve revisão. Planta Daninha, Viçosa, v. 26, n. 3, p. 695-706, 2008. 